\title{
Avaliação do perfil sociodemográfico, clínico, laboratorial e terapêutico dos pacientes com artrite reumatoide em um ambulatório-escola de Teresina, Piauí
}

\author{
Evaluation of the sociodemographic, clinical, laboratorial and therapeutic profile \\ of rheumatoid arthritis patients in an ambulatory school of Teresina, Piauí
} Evaluación de perfil sociodemográfico, laboratorio clínico y terapéutico en pacientes con Artritis Reumatoide en una clínica escuela de Teresina, Piauí

Márcio da Silva PEREIRA ${ }^{1}$

Dayse Caroline Martírios LUZ ${ }^{2}$

Joelma Moreira de Noroes RAMOS ${ }^{3}$

Paulo Brandão Sakr KHOURI ${ }^{4}$

Ronaldo Ewerton VIANA NETO ${ }^{5}$

Cláudio Marcio Fiorenza de SOUZA

Isabella Mota Santa ROSA

Marcelo Augusto Mendes SILVA ${ }^{8}$

André de Gois ROCHA ${ }^{9}$

${ }^{1}$ Acadêmico de Medicina do Centro Universitário Christus (UNICHRISTUS), 60190-060, Fortaleza - Ceará, Brasil

${ }_{2}^{2}$ Médica graduada pela Faculdade Integral Diferencial (FACID), 64999-999, Teresina - PI, Brasil ${ }^{3}$ Médica especialista em Reumatologia pelo HCFM-USP.

Docente da Faculdade Integral Diferencial (FACID), 64999-999, Teresina - PI, Brasil

${ }^{4}$ Acadêmico de Medicina da Universidade Católica de Brasília (UCB), 71966-700, Brasília - DF, Brasil

${ }^{5}$ Acadêmico de Medicina da Universidade Federal do Maranhão (UFMA), 65085-580, São Luís - MA, Brasil

${ }^{6}$ Médico graduado pela Faculdades Integradas Aparício Carvalho (FIMCA), Porto Velho - RO, Brasil

${ }^{7}$ Acadêmico de Medicina da Universidade Federal do Maranhão (UFMA), 65200-000, Pinheiro - MA, Brasil

${ }^{8}$ Acadêmico de Medicina da Universidade Federal do Maranhão (UFMA), 65200-000, Pinheiro - MA, Brasil

${ }^{9}$ Médico graduado pela Universidade Federal de Campina Grande (UFCG), 58900-000, Cajazeiras - PB, Brasil

\section{Resumo}

A artrite reumatoide é uma doença inflamatória auto-imune de distribuição mundial, sendo 2 a 3 vezes mais freqüente nas mulheres que nos homens. De etiologia desconhecida, afeta as articulações sinoviais periféricas, de forma simétrica e progressiva, levando à dor, edema articular e rigidez matinal. Quando não tratada, evolui com limitações funcionais graves. O propósito deste trabalho é descrever o perfil sociodemográfico, clínico-laboratorial e terapêutico dos pacientes com artrite reumatoide acompanhados em um ambulatório-escola de reumatologia, em Teresina-PI. Para tanto, desenvolveu-se um estudo retrospectivo com corte transversal observacional e abordagem quantitativa, analisando-se prontuários de pacientes portadores de artrite reumatoide, conforme formulário previamente elaborado no ambulatório de reumatologia da Clínica Escola de uma Instituição de Ensino Superior em Teresina-PI, durante o período de 2010 a 2014 . Do total de 60 prontuários selecionados, $90 \%$ eram do sexo feminino. Os pacientes apresentaram uma idade média de 46,3 anos. A maior parte dos pacientes apresentou tempo de duração dos sintomas superior a um ano (63\%). As principais articulações acometidas foram mãos $(21,8 \%)$ e punhos $(16,1 \%)$. As provas de atividade inflamatória mostraram-se alteradas ao diagnóstico (VHS $76,7 \%$ e PCR $55 \%$ ). O fator reumatoide foi positivo em $23,3 \%$ dos pacientes e, apenas $13,3 \%$ realizaram anti-CCP. No tratamento predominou a associação do metotrexato com anti-maláricos, AINES, analgésicos ou corticóides. Concluiu-se que o presente estudo proporcionou uma visão parcial do perfil epidemiológico de pacientes com artrite reumatoide no estado do Piauí, identificando pontos importantes em relação às características demográficas e clínicas, os tipos de tratamentos farmacológicos e a pequena utilização de marcadores de doença.

Descritores: Artrite Reumatoide; Fator Reumatoide; Terapêutica.

\begin{abstract}
The Rheumatoid Arthritis is an auto-immune inflammatory disease of worldwide distribution and occurs 2 to 3 times more frequently in women than men. Of unknown etiology, it affects the peripheral synovial joints, symmetrically and progressively, leading to pain, joint edema and morning stiffness. If it is not treated evaluates to severe functional limitation. It was objectified describes the sociodemographic profile, the clinical-laboratory and the therapeutic of patients with Rheumatoid Arthritis (RA) followed in ambulatory school of rheumatology in Teresina-PI. It was developed a retrospective study with observational cross-cut and quantitative approach, analyzing medical records of patient RA carrier, according to formulary previously elaborated on clinical school of an Institution of Higher Education in Teresina-PI, during the period from 2010 to 2014. The total of 60 charts selected, $90 \%$ were females. Patients had a mean age of 46.3 years. The majority of patients had duration of symptoms longer than one year (63\%). The main joints affected were hands $(21.8 \%)$ and wrists $(16.1 \%$ ). The evidence of inflammatory activity was altered at diagnosis (HSV 76.7\% and PCR 55\%). The rheumatoid factor was positive in $23.3 \%$ of the patients, and only $13.3 \%$ performed anti-CCP. In the treatment, the association of methotrexate with antimalarial, NSAIDs, analgesics or steroids predominated. This study provided a partial view of the epidemiological profile of patients with RA in the State of Piauí, identifying important points regarding demographic and clinical characteristics, types of pharmacological treatments and the small use of disease markers.

Descriptors: Arthritis; Rheumatoid Factor; Therapeutics.
\end{abstract}

\section{Resumen}

La artritis reumatoide es una enfermedad inflamatoria autoinmune de la distribución en todo el mundo, de 2 a 3 veces más frecuente en mujeres que en hombres. De etiología desconocida, afecta a las articulaciones sinoviales periféricos de forma simétrica y progresiva, dando lugar a dolor, hinchazón de las articulaciones y la rigidez matinal. Si no se trata, progresa a limitaciones funcionales graves. Se evaluó describir la sociodemográficos, clínicos, de laboratorio y terapéutico de los pacientes con artritis reumatoide tratados en una clínica-escuela de la reumatología en Teresina-PI. Desarrollaron un estudio retrospectivo con enfoque cuantitativo transversal y observacional, el análisis de las historias clínicas de los pacientes con artritis reumatoide, como forma elaborada previamente en la clínica de reumatología de la Escuela clínica de una institución de educación superior en Teresina-PI, durante el periodo de 2010 a 2014. Los resultados de los 60 registros seleccionados, el $90 \%$ eran mujeres. Los pacientes tenían una edad media de 46,3 años. La mayoría de los pacientes tenían una mayor duración de los síntomas más de un año $(63 \%)$. Las principales articulaciones afectadas fueron las manos $(21,8 \%)$ y mangos $(16,1 \%)$. La actividad inflamatoria demostrado ser cambiado en el diagnóstico (76,7\% VSG y PCR 55\%). El factor reumatoide fue positivo en el $23,3 \%$ de los pacientes y sólo el 13,3\% tenía anticuerpos anti-CCP. En el tratamiento asociación predominante de metotrexato con medicamentos contra la malaria, AINE, analgésicos o corticoides. Este estudio proporciona una visión parcial del perfil epidemiológico de los pacientes con artritis reumatoide en el estado de Piauí, identificando los puntos importantes en relación a características demográficas y clínicas, tipos de tratamientos farmacológicos y poco uso de marcadores de la enfermedad.

Descriptores: Artritis Reumatoide; Factor Reumatoide; Terapéutica 


\section{INTRODUÇÃO}

A artrite reumatoide (AR) é uma doença auto-imune, inflamatória crônica, de etiopatogenia, grande parte, desconhecida e complexa, que se caracteriza pelo surgimento de sinovite, acometendo, principalmente as articulações periféricas de mãos e punhos, de forma progressiva e predominantemente simétrica. Essa patologia acomete $1 \%$ da população adulta, sendo mais comum no sexo feminino, na proporção de $3: 1$, respectivamente, iniciando-se, principalmente, nas $4^{\circ}$ e $5^{\circ}$ décadas de vida ${ }^{1}$.

A maior parte dos pacientes com artrite reumatoide desenvolve um quadro de início insidioso com rigidez e/ou edema de várias articulações, especialmente em mãos, punhos, tornozelos e pés ${ }^{2,3}$.

As características demográficas e clínicas da AR varia de acordo com a população acometida. $\mathrm{Na}$ atualidade, a maior parte das informações disponível na literatura tem origem no continente europeu e Estados Unidos. Poucos estudos foram desenvolvidos na população brasileira e principalmente na região nordeste ${ }^{2}$.

No diagnóstico da artrite reumatoide consideram-se achados clínicos e exames complementares. Nenhum teste, laboratorial, de imagem ou histopatológico, se considerado de forma isolada, será capaz de confirmar o diagnóstico ${ }^{3}$.

O tratamento sempre deve ser iniciado após o estabelecimento do diagnóstico definitivo de AR objetivando-se a melhora dos sintomas, controle da destruição articular bem como também da limitação funcional ${ }^{4}$.

Apesar dos esforços envidados a fim de se ampliar o entendimento e racionalizar o manejo da $\mathrm{AR}$, os estudos de prevalência não revelam a real situação da AR em nosso meio, pois os pacientes com doença crônica estável podem estar sendo superestimados. A revisão (retrospectiva ou prospectiva) de casos acompanhados em serviços ambulatoriais é uma forma de avaliar as características dos portadores de doenças crônicas, particularmente as com baixa prevalência ${ }^{4}$.

Diante do exposto, o presente estudo propôs-se a coletar informações sobre as características demográficas e clínicas de pacientes com artrite reumatoide em acompanhamento ambulatorial em Teresina-Piauí, para avaliação mais apurada de sua evolução e do estágio de tratamento.

\section{MATERIAL E MÉTODO}

Desenvolveu-se um estudo retrospectivo com corte transversal observacional e abordagem quantitativa, analisando-se prontuários de pacientes atendidos no ambulatório de reumatologia da Clínica Escola de uma Instituição de Ensino Superior Particular em Teresina-PI entre o período de 2010 a 2014.

Realizou-se a pré-seleção dos prontuários pela consulta no Sistema de Arquivamento de Dados, em que estes foram separados, triados e excluídos conforme os critérios de exclusão, obtendo-se uma amostra composta por 60 prontuários.

Foram inclusos no estudo os pacientes com diagnóstico confirmado de Artrite Reumatoide e que tiverem ao menos um retorno de acompanhamento. Foram excluídos os pacientes com afecção reumática sem diagnostico definido para Artrite Reumatoide, prontuários ilegíveis ou que apresentaram dificuldade de compreensão e os prontuários não localizados na busca do sistema de arquivamento.
A coleta de dados ocorreu por meio da análise de informações presentes nos prontuários, preenchendo-se o formulário previamente elaborado pelos autores da pesquisa. As variáveis utilizadas no estudo foram gênero, idade, queixa principal, tempo de duração dos sintomas, principais articulações acometidas, presença de artralgia, presença de rigidez matinal, presença de edema articular, provas de atividade inflamatória, fator reumatoide, anti-CCP, Rx de mãos e punhos, terapêutica instituída, quadro clínico, radiografias e terapêutica foram abordadas ao diagnóstico e após 3 e 6 meses do mesmo.

O estudo respeitou as disposições éticas advindas da resolução no 196/96, do Conselho Nacional de Saúde/ Ministério da Saúde referente a estudos envolvendo seres humanos (Brasil, 1996). A coleta de dados iniciou-se, após ser autorizada pelo Fiel Depositário dos prontuários e ser aprovada pelo CEP da Instituição. O anonimato dos sujeitos da pesquisa foi garantido, visto que os dados divulgados não identificaram pacientes e todas as informações foram mantidas sob sigilo, sendo utilizadas apenas para o estudo.

Os dados coletados foram organizados em planilhas do Excel 2010 e, posteriormente, analisados através de uma estatística descritiva, sendo utilizado o software SPSS (Statistical Package for the Social Scienses) 17.0. Para melhor apresentação e compreensão das informações, estas foram designados sobre a forma de tabelas e gráficos.

\section{RESULTADOS E DISCUSSÃO}

Dos 60 pacientes portadores de Artrite Reumatoide (AR) acompanhados no ambulatório de reumatologia no período de 5 anos, o gênero feminino representou $90 \%$ dos casos, originando relação sexo feminino/sexo masculino de 9:1. Os pacientes apresentaram uma idade média de 46,3 anos (mediana =46, mínimo: 24 e máxima: 74, DP: 12,75).

De acordo com a literatura, o gênero feminino é mais afetado pela artrite reumatoide que o gênero masculino em uma proporção de aproximadamente $3: 1$, sendo que alguns estudos ressaltam pior prognóstico relacionado ao sexo feminino. Estudos entre a população brasileira demonstram proporção sexo feminino/masculino de 9:1, corrobando com a proporção observada nesse estudo ${ }^{5,6}$.

A maior parte dos pacientes apresentou tempo de duração dos sintomas superior a 12 meses $(63,3 \%)$, seguida de $20 \%$ dos pacientes com presença da sintomatologia entre 6 e 12 meses e 16,7\% com menos de 6 meses de duração da clínica (Tabela 1).

Dentre os principais sintomas apresentados pelos pacientes na primeira consulta, a artralgia foi a manifestação mais comum, presente em $100 \%$ dos casos. O edema articular esteve presente em $86,7 \%$ e a rigidez matinal em $76,7 \%$ dos pacientes. Ao diagnóstico, $30 \%$ dos pacientes já apresentavam algum grau de limitação funcional.

Tabela 1. Tempo de duração dos sintomas referidos pelos pacientes durante o atendimento

\begin{tabular}{cc}
\hline $\begin{array}{c}\text { Tempo de duração } \\
\text { dos sintomas }\end{array}$ & $\begin{array}{c}\text { Número de } \\
\text { pacientes }\end{array}$ \\
\hline$<$ 6meses & $10(16,7 \%)$ \\
\hline 6meses - 12meses & $12(20 \%)$ \\
$>12$ meses & $38(63,3 \%)$ \\
\hline
\end{tabular}

As articulações das mãos e punhos foram as principais articulações acometidas na população em estudo, 
representando $21,8 \%$ e $16,1 \%$ respectivamente (Gráfico 1 ). Esses dados são coerentes aos referidos por Moreira et al. ${ }^{3}$.

Quanto as provas de atividade inflamatória, ao diagnóstico, o resultado do VHS encontrava-se dentro da faixa de normalidade $(<20 \mathrm{~mm} / \mathrm{h})$ em $23,3 \%$ dos pacientes ao passo que o PCR encontrava-se normal $(<6 \mathrm{mg} / \mathrm{dL})$ em $45 \%$. Após seis meses de tratamento, esse número aumentou respectivamente para $53,3 \%$ e $83,3 \%$, sugerindo um controle de atividade da doença, similarmente aos estudos de Abreu et al. ${ }^{7}$.

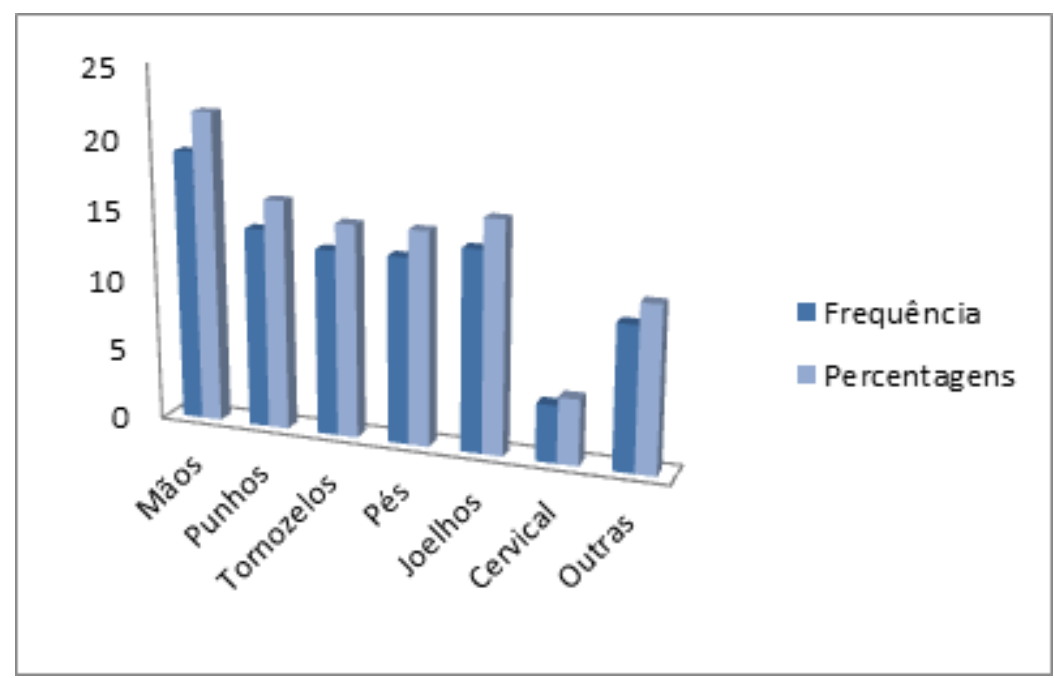

Gráfico 1. Frequência de acometimento articular na AR

Ao diagnóstico, apenas 14 pacientes $(23,3 \%)$ apresentaram FR positivo. A porcentagem de positividade para o anti-CCP, no presente estudo, mostrou-se inferior à relatada por diversos outros estudos. Não se individualizou os diferentes isotipos do FR, nem tampouco se ressaltou os métodos utilizados para pesquisa do FR (Waaler-Rose, nefelometria, ELISA) $)^{3,7}$.

Entre a amostra estudada, apenas 8 pacientes realizaram anti-CCP, e entre estes, $75 \%$ apresentaram títulos elevados. O pequeno número de pacientes que realizaram a dosagem desse anticorpo reflete as baixas condições econômicas da população desse estudo, visto que o SUS não disponibiliza esse exame ${ }^{7}$.

A expressão de positividade observada nessa pesquisa foi semelhante à observada por Silva et al. ${ }^{5}$. Vários estudos têm demonstrado que o anti-CCP apresenta melhor desempenho diagnóstico do que o FR, mas que a utilização combinada desses testes mostra um melhor desempenho diagnóstico do que os testes isolados ${ }^{5}$.

Ao diagnóstico, 32 pacientes não possuíam qualquer alteração radiológica. Entre os que apresentavam alteração, o desalinhamento ósseo correspondeu ao principal comprometimento observado, presente em 14 pacientes (Tabela 2). Não se encontrou o acompanhamento radiológico sistemático do comprometimento articular, por questões já mencionadas anteriormente, como amostra ser assistida pelo SUS, encontrando inúmeras dificuldades na marcação dos exames e nas consultas de acompanhamento clínico. Além disso, as imagens radiológicas apresentadas pelos pacientes não possuem uma boa qualidade o que dificultou, em partes, essa avaliação.

$\mathrm{Na}$ Tabela 3 está representado o perfil dos medicamentos utilizados para o tratamento dos pacientes com AR. O medicamento imunomudulador mais utilizado foi o metotrexato (MTX), em associação ou combinado com outras medicações, somando-se o uso em um total de 79,9\%. Segundo Mota et al. ${ }^{8}$ o MTX é um agente considerado o fármaco padrão ouro no tratamento da $\mathrm{AR}^{9}$.

Dentre as medicações combinadas ao MTX, os antimaláricos foram os mais observados $(46,6 \%)$, semelhante ao valor encontrado por Gomes et al. ${ }^{2}$ e relatado na literatura ${ }^{10}$.

Uma característica importante foi que a maioria dos pacientes estava em uso de corticoesteróides, por via oral. Nesse estudo não se observou pacientes em uso de imunobiológicos, notando-se que grande parte apresentou remissão da atividade da doença.

$\mathrm{Na}$ segunda consulta, após, aproximadamente seis meses de tratamento, em $50 \%$ dos casos ocorreu ajuste das doses das medicações, conforme períodos de crises e remissões de sintomas. Os outros $50 \%$ não necessitaram desse ajuste, permanecendo com o esquema proposto ao diagnóstico.

Com a terapêutica instituída, $86,7 \%$ dos pacientes referiram melhora do quadro clínico, apresentando remissão da atividade da doença. O restante dos pacientes $(13,3 \%)$ não relatou melhora dos sintomas, observando-se que estes não aderiram adequadamente ao tratamento proposto.

Tabela 2. Perfil radiológico dos pacientes portadores de artrite reumatoide

\begin{tabular}{|c|c|c|}
\hline Articulação & Achado radiográfico & $\mathbf{n}$ \\
\hline \multirow[t]{6}{*}{ Mãos } & Desalinhamento articular & 14 \\
\hline & Desmineralização óssea & 8 \\
\hline & $\begin{array}{l}\text { Diminuição dos espaços } \\
\text { articulares }\end{array}$ & 6 \\
\hline & Edema em partes moles & 2 \\
\hline & Erosões ósseas & 4 \\
\hline & Sinovite & 2 \\
\hline \multirow[t]{4}{*}{ Punhos } & Desalinhamento articular & 4 \\
\hline & Desmineralização óssea & 6 \\
\hline & $\begin{array}{l}\text { Diminuição dos espaços } \\
\text { articulares }\end{array}$ & 2 \\
\hline & Erosões ósseas & 2 \\
\hline Pés & Desalinhamento articular & 2 \\
\hline Tornozelos & \multicolumn{2}{|c|}{ Dados não relatados nos prontuários } \\
\hline
\end{tabular}

Tabela 3. Perfil dos medicamentos utilizados para o tratamento dos pacientes com Artrite Reumatoide $(\mathrm{N}=60)$

\begin{tabular}{ll}
\hline Medicamentos & n (\%) \\
\hline $\begin{array}{l}\text { MTX e/ou CE e/ou analgésicos } \\
\text { MTX e anti-maláricos }\end{array}$ & $20(33,3 \%)$ \\
\hline $\begin{array}{l}\text { MTX e/ou anti-maláricos e/ou analgésicos } \\
\text { e/ou CE }\end{array}$ & $26(43,3 \%)$ \\
\hline $\begin{array}{l}\text { Leflunomida e/ou AINES e/ou analgésicos } \\
\text { e/ou CE }\end{array}$ & $2(1,1 \%)$ \\
\hline $\begin{array}{l}\text { Antimaláricos e/ou AINES e/ou analgésicos } \\
\text { e/ou CE }\end{array}$ & $10(16,7 \%)$ \\
\hline
\end{tabular}

\section{CONCLUSÃO}

As características demográficas e clínicas dos pacientes acompanhados neste estudo foram coerentes em 
vários aspectos com outras pesquisas anteriormente publicadas. A AR prevaleceu no gênero feminino, originando relação gênero feminino com idade média de 46,3 anos.

A maior parte dos pacientes já apresentava as queixas clínicas há mais de um ano. Os achados com relação aos aspectos laboratoriais, incluindo a positividade de anti-CCP, são semelhantes a outras populações. No entanto, a prevalência de FR mostrou-se menor em comparação a outras publicações.

A maior parte dos pacientes relatou melhora dos sintomas após adesão à terapêutica. A droga de escolha foi o metotrexato. $\mathrm{O}$ tratamento requer um acompanhamento sistemático e periódico do paciente, com monitorização da atividade da doença, progressão radiológica, avaliação da capacidade funcional e avaliação do prognóstico.

Ainda há muitas dúvidas e dificuldades no manejo dessa enfermidade. $\mathrm{O}$ diagnóstico precoce, que representa um passo primordial, muitas vezes é prejudicado pelas diversas falhas no atendimento do SUS e pela falta de informação que ainda circunda essa enfermidade.

\section{REFERENCIAS}

1. Sato EI. Guia de medicina ambulatorial e hospitalar da UNIFESP/EPM Reumatologia. 2 ed. São Paulo: Editora Manole; 2010.

2. Gomes RKS, Pires FA, Nobre MRC, de Sá Marchi MF, Rickli JCK. Impacto da artrite reumatoide no sistema público de saúde em Santa Catarina, Brasil: análise descritiva e de tendência temporal de 1996 a 2009. Rev Bras Reumatol. 2016. DOI: 10.1016/j.rbr.2016.05.003

3. Moreira C, Pinheiro GRC, Marques Neto JF. Reumatologia essencial. 1.ed. Rio de Janeiro: Guanabara Koogan; 2009.

4. Mota LMH, Laurindo IMM, Santos Neto LL. Artrite reumatoide inicial: conceitos. Rev Assoc Med Bras 2010; 56(2): 227-9

5. Silva AF, Matos NA, Lima MAS, Lima EF, Gaspar AP, Braga JAF, et al. Valor Diagnóstico do Anticorpo Antipeptídeo Citrulinado Cíclico na Artrite Reumatóide. Rev Bras Reumatol. 2006; 46(3):174-80.

6. Prado ADD. Achados inflamatórios e dano estrutural vistos por ultrassonografia em pacientes com artrite reumatoide: correlação com dados clínicos, linfócitos $\mathrm{T}$ regulatórios e TH-17 e citocinas inflamatórias no sangue periférico [tese]. Porto Alegre: Pontifícia Universidade Católica do Rio Grande do Sul; 2016.

7. Abreu MM, Kowalski SC, Ciconelli RM, Ferraz MB. Avaliação do perfil sociodemográfico, clínicolaboratorial e terapêutico dos pacientes com artrite reumatóide que participaram de projetos de pesquisa na Escola Paulista de Medicina, nos últimos 25 anos. Rev Bras Reumatol. 2006;46(2):103-9.

8. Mota LMH, Cruz B, Brenol C, Pereira I, RezendeFronza L, Bertolo M, et al. Consenso 2012 da Sociedade Brasileira de Reumatologia para o tratamento da artrite reumatoide. Rev Bras Reumatol. 2012; 52(2):152-74.

9. Goeldner I, Skare TL, Reason ITM, Utiyama SRR. Artrite reumatoide: uma visão atual. J Bras Patol Med Lab. 2011; 47(5):495-503.

10. Fauci A, Braunwald E, Kasper D. Harrison. Princípios de medicina interna. Vol. I. 17 ed. Distrito Federal: McGraw-Hill Interamericana; 2009.

\section{CONFLITO DE INTERESSES}

Os autores declaram não haver conflitos de interesse.

\section{AUTOR PARA CORRESPONDÊNCIA}

\section{Márcio da Silva Pereira}

marcio7x@ hotmail.com.br

Submetido em 28/01/2017 Aceito em 20/02/2017 